\title{
Transactions
}

Cite this: Dalton Trans., 2011, 40, 4871

wWw.rsc.org/dalton

PAPER

\section{Aqueous pathways for the formation of zinc oxide nanoparticles $\dagger$}

\author{
Amir Moezzi, Michael Cortie* and Andrew McDonagh \\ Received 12th December 2010, Accepted 18th February 2011 \\ DOI: 10.1039/c0dt01748e
}

\begin{abstract}
We examine the effect of reactant concentrations, temperatures and feeding methods on the morphology of $\mathrm{ZnO}$ formed when reacting solutions of $\mathrm{ZnSO}_{4}$ and $\mathrm{NaOH}$. The catalytic effect of hydroxide in excess relative to the stoichiometric ratio is considered. It is shown that, having fixed other reaction conditions, the end-products, particle structures and size strongly depend on the mole ratio of the precursors. The presence of zinc salt hydroxide species was confirmed at sub-stoichiometric ratios in slightly acidic conditions. At the stoichiometric ratio both zinc hydroxide and zinc oxide are formed, while only zinc oxide forms in an excess of hydroxide. The method of feeding the reactants into the reaction vessel also has a strong influence on the end-product properties, as does the reaction temperature. By control of these parameters the specific surface area could be varied from 10 to $33 \mathrm{~m}^{2}$ $\mathrm{g}^{-1}$, the particle shape could be varied from equiaxed, through to star-like and needle-like, and the particle size may be varied from 50 to over $300 \mathrm{~nm}$.
\end{abstract}

\section{Introduction}

Zinc oxide is an important material utilized in a diversity of industrial, biomedical, cosmetic and scientific applications. High volume uses include as an ingredient in rubber tires and as a pigment in corrosion-resisting paints. In addition, it has a number of small volume, high-tech applications such as in gas sensors, piezoelectric materials, transparent conducting oxide films, phosphors, UV blocking agents, anti-bacterial ointments or catalysts. ${ }^{1-4}$ High-temperature, gas-phase routes are currently the preferred method to produce $\mathrm{ZnO}$ particles for bulk industrial use, ${ }^{5,6}$ while hydrothermal techniques can be used to grow single crystals suitable for some advanced applications. ${ }^{7}$ However, a large number of low-temperature wet-chemical methods are also possible and provide access to particles with different structures and properties than those produced by gas-phase or hydrothermal syntheses. In particular, precipitation reactions in unpressurised aqueous media offer relatively low cost compared to other methods of synthesis.

The shape and size of zinc oxide crystals formed from aqueous solutions is quite variable. A number of prior studies have investigated the aqueous-phase synthesis of zinc oxide and the principles are now broadly understood. ${ }^{7-14}$ However, there is still considerable uncertainty regarding the possible role of zinc hydroxide in this process, the mechanism by which the zinc hydroxide (if it forms) converts to zinc oxide, and the factors effecting product morphology. There are conditions which evidently lead directly to the precipitation of $\mathrm{ZnO}^{10,11}$ and others in which an intermediate

Institute for Nanoscale Technology, University of Technology Sydney, Sydney, NSW, 2007, Australia.E-mail:michael.cortie@uts.edu.au; Tel: +61 295142208

$\dagger$ Electronic supplementary information (ESI) available: XRD data, TGA comparison charts and SEM images. See DOI: 10.1039/c0dt01748e
$\mathrm{Zn}(\mathrm{OH})_{2}$ phase has been demonstrated ${ }^{10}$ or claimed. ${ }^{12}$ It is observed that this intermediate phase can convert to $\mathrm{ZnO}$ by the mechanism of dissolution-precipitation ${ }^{13}$ or by solid state transformation..$^{10,12}$ There is evidently also an interplay between kinetics and thermodynamics in these processes. For example, it is claimed ${ }^{15}$ that zinc hydroxide can be electrolytically precipitated at room temperature from a system of $\mathrm{Zn}^{2+}$ and $\mathrm{OH}^{-}$in contradiction to thermodynamic predictions. However, at higher temperatures $\mathrm{ZnO}$ is always the more likely end product. ${ }^{14-16}$ Other studies have examined the very significant effects of process variables such as stirring, temperature or $\mathrm{pH}$ on the identity and morphology of the product. ${ }^{9,10,13,14}$

Here we provide a comprehensive analysis of the effect of critical reaction parameters on the morphology of the $\mathrm{ZnO}$ particles prepared in the $\mathrm{H}_{2} \mathrm{O} / \mathrm{Zn}^{2+} / \mathrm{OH}^{-}$system at temperatures less than $90{ }^{\circ} \mathrm{C}$. Importantly, an understanding of the mechanisms and phenomenology of formation provide a means to control the shape and size of $\mathrm{ZnO}$ particles produced by this route.

In aqueous environments, the following reactions are the main contributors to the formation of zinc oxide: ${ }^{17-20}$

$$
\begin{gathered}
\mathrm{Zn}_{(\mathrm{aq})}^{2+}+\mathrm{OH}_{(\mathrm{aq})}^{-} \rightarrow \mathrm{Zn}(\mathrm{OH})_{(\mathrm{aq})}^{+} \\
\mathrm{Zn}(\mathrm{OH})_{(\mathrm{aq})}^{+}+\mathrm{OH}_{(\mathrm{aq})}^{-} \rightarrow \mathrm{Zn}(\mathrm{OH})_{2(\mathrm{~s})} \\
\mathrm{Zn}(\mathrm{OH})_{2(\mathrm{~s})} \leftrightarrows \mathrm{Zn}(\mathrm{OH})_{2(\mathrm{aq})} \\
\mathrm{Zn}(\mathrm{OH})_{2(\mathrm{aq})}+\mathrm{OH}_{(\mathrm{aqu})}^{-} \rightarrow \mathrm{Zn}(\mathrm{OH})_{3(\mathrm{aq})}^{-} \\
\mathrm{Zn}(\mathrm{OH})_{3(\mathrm{aq})}^{-}+\mathrm{OH}_{(\mathrm{aq})}^{-} \rightarrow \mathrm{Zn}(\mathrm{OH})_{4(\mathrm{aq})}^{2-}
\end{gathered}
$$




$$
\begin{gathered}
\mathrm{Zn}(\mathrm{OH})_{2(\mathrm{aq})} \rightarrow \mathrm{ZnO}_{(\mathrm{s})}+\mathrm{H}_{2} \mathrm{O}_{(\mathrm{l})} \\
\mathrm{Zn}(\mathrm{OH})_{2(\mathrm{~s})} \rightarrow \mathrm{ZnO}_{(\mathrm{s})}+\mathrm{H}_{2} \mathrm{O}_{(\mathrm{l})} \\
\mathrm{Zn}(\mathrm{OH})_{3(\mathrm{aq})}^{-} \rightarrow \mathrm{ZnO}_{(\mathrm{s})}+\mathrm{H}_{2} \mathrm{O}_{(\mathrm{l})}+\mathrm{OH}_{(\mathrm{aq})}^{-} \\
\mathrm{Zn}(\mathrm{OH})_{4(\mathrm{aq})}^{2-} \rightarrow \mathrm{ZnO}_{(\mathrm{s})}+\mathrm{H}_{2} \mathrm{O}_{(\mathrm{l})}+2 \mathrm{OH}_{(\mathrm{aq})}^{-}
\end{gathered}
$$

These reactions are primarily governed by the $\mathrm{pH}$ of the system. Eqn (1) to (5) describe the formation of zinc hydroxide complexes. The species formed in eqn (1) is shown as $\mathrm{Zn}(\mathrm{OH})^{+}$for clarity, but a zinc hydroxide salt complex with the general formula of $\mathrm{Zn}_{a}(\mathrm{OH})_{b}\left(\mathrm{X}^{c-}\right)_{(2 a-b) / c} \cdot n \mathrm{H}_{2} \mathrm{O}$ (where $\mathrm{X}$ may be, for example, $\mathrm{Cl}^{-}$, $\mathrm{NO}_{3}{ }^{-}, \mathrm{CO}_{3}{ }^{2-}, \mathrm{CH}_{3} \mathrm{COO}^{-}$or $\mathrm{SO}_{4}{ }^{2-}$ ) is often produced ${ }^{21}$ when the concentration of $\mathrm{OH}^{-}$is less than that required to produce $\mathrm{Zn}(\mathrm{OH})_{2}$. These zinc hydroxide salt complexes vary in solubility depending on the anion, $\mathrm{X}$. When the $\mathrm{OH}^{-}: \mathrm{Zn}^{2+}$ molar ratio is $2: 1$ (eqn (2)), the reaction product is $\mathrm{Zn}(\mathrm{OH})_{2} \cdot{ }^{22,23} \mathrm{Zn}(\mathrm{OH})_{2}$ has low solubility in water $\left(K_{\mathrm{sp}}=3.5 \times 10^{-17} \text { at } 25^{\circ} \mathrm{C}\right)^{14,18}$ and is stable, for example it has been reported to remain unchanged after six months in water at room temperature. ${ }^{24}$ Eqn (4) and (5) indicate that if more hydroxide is added, soluble higher-order hydroxo-complexes of zinc may be formed. Importantly, these can decompose to $\mathrm{ZnO}$, releasing hydroxide ions and water (eqn (8) and (9)).

The solubility of the zinc-containing species is an important consideration in the pathway to the formation of $\mathrm{ZnO}$. The fraction of zinc species such as $\mathrm{Zn}_{(\text {aq) }}^{2+}, \mathrm{Zn}(\mathrm{OH})_{(\mathrm{aq})}^{+}, \mathrm{Zn}(\mathrm{OH})_{2(\text { aq) }}$, $\mathrm{Zn}(\mathrm{OH})_{3(\text { aq })}^{-}$and $\mathrm{Zn}(\mathrm{OH})_{4(\mathrm{aq})}^{2-}$ in solution varies over a range of $\mathrm{pH}$ at $25^{\circ} \mathrm{C} . .^{15,17,18}$ In acidic conditions $(\mathrm{pH}<6), \mathrm{Zn}^{2+}$ is the main ion present in solution, in neutral to slightly basic conditions most $\mathrm{Zn}$ is present as solid $\mathrm{Zn}(\mathrm{OH})_{2}$ or $\mathrm{ZnO}$ which both have very low solubility products in this range of $\mathrm{pH}$, while at $\mathrm{pH}=$ 12 or above, the main zinc species is $\mathrm{Zn}(\mathrm{OH})_{4}{ }^{2-} \cdot{ }^{25} \mathrm{In}$ such alkaline conditions precipitation of $\mathrm{ZnO}$ does not occur due to the stability of $\mathrm{Zn}(\mathrm{OH})_{4(\mathrm{aq})}^{2-}$ ions ${ }^{13,26}$ according to eqn (4) and (5). The relatively low solubility of $\mathrm{Zn}(\mathrm{OH})_{2}$ and $\mathrm{ZnO}$ over the range of intermediate $\mathrm{pH}$ values is an important aspect of the present work. Seven crystal forms of $\mathrm{Zn}(\mathrm{OH})_{2}$ have been reported with $\varepsilon-\mathrm{Zn}(\mathrm{OH})_{2}$ being the most stable. ${ }^{16,17,20}$ Because of the relative stability of solid $\mathrm{Zn}(\mathrm{OH})_{2}$, it is important that this species is either avoided or re-solubilized if timely formation of the even more stable solid $\mathrm{ZnO}$ is to be achieved. Polynuclear zinc complexes such as $\mathrm{Zn}_{2}(\mathrm{OH})^{3+}{ }_{\text {(aq) }}$ and $\mathrm{Zn}_{2}(\mathrm{OH})_{6(\text { aq })}^{2-}$ and $\mathrm{Zn}_{4}(\mathrm{OH})_{4(\text { aq })}^{4+}$ may also be present at high total zinc concentrations. ${ }^{17}$

Temperature also plays an important role in the synthesis of nanoparticles by changing the kinetics of the above-mentioned precipitation reactions. The decomposition of solid zinc hydroxide to $\mathrm{ZnO}$ and $\mathrm{H}_{2} \mathrm{O}_{\text {(1) }}$ is endothermic at room temperature ${ }^{27}(\Delta H=$ $+9.11 \mathrm{~kJ} \mathrm{~mol}^{-1}$ using the data of Goux et al. $\left.{ }^{15}\right)$ but $\Delta G$ is slightly negative $\left(\Delta G=-1.7 \mathrm{~kJ} \mathrm{~mol}^{-1}\right)$. Values of the thermodynamic parameters can be calculated at other temperatures from knowledge of the specific heat capacities and are plotted in Fig. 1. Clearly, the conversion of $\mathrm{Zn}(\mathrm{OH})_{2}$ to $\mathrm{ZnO}$ will be increasingly favored at higher temperatures, both from a free energy and a kinetic perspective. ${ }^{16}$ In this work, we report on the interplay of these

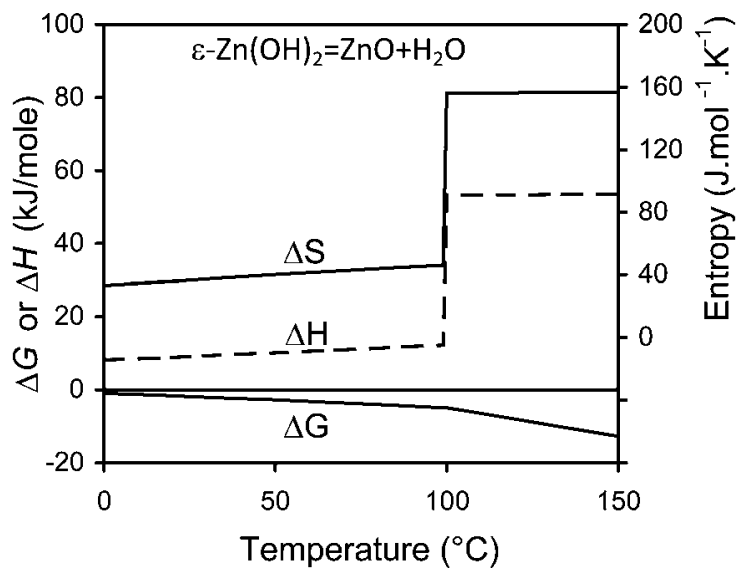

Fig. 1 Thermodynamic parameters for the reaction of solid $\varepsilon-\mathrm{Zn}(\mathrm{OH})_{2}$ to solid $\mathrm{ZnO}$ and $\mathrm{H}_{2} \mathrm{O}$. The values are computed from the standard states at $298 \mathrm{~K}$ at 1 atmosphere using the specific heat capacities from reference. ${ }^{15}$

reaction parameters and examine their effect on the properties of zinc-containing products using aqueous reaction conditions at temperatures less than $90^{\circ} \mathrm{C}$ and at atmospheric pressure.

\section{Experimental}

\section{General}

Zinc sulfate heptahydrate (AR grade) and sodium hydroxide pellets (AR grade) were purchased from Ajax Chemicals and used as-received. De-ionised water was used as the solvent. Reactions were conducted under atmospheric conditions using a two-neck round bottom flask with a digitally-controlled magnetic heater/stirrer. A magnetic stirrer bar was used at a stirring rate of $820 \mathrm{rpm}$. Precipitates were isolated by centrifugation at 4400 $\mathrm{rpm}$ followed by drying using a rotary evaporator at $70^{\circ} \mathrm{C}$, unless otherwise stated.

X-ray diffraction data of powder samples were collected using a Siemens D5000 X-ray Diffractometer with a graphite post monochromator with the following parameters: wavelength 1.5406 $\AA(\mathrm{Cu} \mathrm{Ka})$, tube power $1.6 \mathrm{~kW}(40 \mathrm{kV}$ at $40 \mathrm{~mA})$, step size $=0.02^{\circ}$, time per step $=2 \mathrm{~s}$, divergent slit $=1^{\circ}$, receiving slit $=0.02 \mathrm{~mm}$, scan angle range $=3-80^{\circ}$. Scanning electron microscopy images were obtained using a Zeiss Supra 55VP SEM operating in high vacuum mode. An accelerating voltage of $5-20 \mathrm{kV}$ was used with $10-30 \mu \mathrm{m}$ aperture and images were obtained using an in-lens secondary detector.

Thermogravimetric analysis (TGA) experiments were performed using a TA Instruments SDT 2960 with simultaneous DTA-TGA. A heating rate of $5{ }^{\circ} \mathrm{C} \mathrm{min}^{-1}$ was used in a nitrogen atmosphere. BET specific surface area measurements were performed using an Autosorb-1 from Quantachrome Instruments by a precise vacuum volumetric method for nitrogen chemisorption. Multi-point (5 points) measurement was conducted on each sample.

Thermodynamic data for the formation of $\mathrm{ZnO}$ from $\mathrm{Zn}^{2+}$ and $\mathrm{OH}^{-}$were calculated for reactions at $298 \mathrm{~K}$ and 1 atm. Standard enthalpies and Gibbs free energies of the reactions were calculated using the available thermodynamic data. ${ }^{17,28}$ The solubility product for $\mathrm{ZnO}$ was obtained from ref. 19 and that of $\mathrm{Zn}(\mathrm{OH})_{2}$ from ref. 18 . 
Table 1 Zinc sulfate to sodium hydroxide mole ratio. The $\mathrm{pH}$ of the resultant mixtures after reaction was in the range of 11 to 12

\begin{tabular}{lllllllll}
\hline Reaction & A & B & C & D & E & F & G & H \\
\hline $\begin{array}{l}\mathrm{Zn}^{2+}: \mathrm{OH}^{-} \text {mole } \\
\text { ratio }\end{array}$ & $1: 2$ & $1: 2.3$ & $1: 2.5$ & $1: 3$ & $1: 3.5$ & $1: 4$ & $1: 5$ & $1: 6$ \\
\hline
\end{tabular}

\section{Reactant stoichiometry}

Aqueous solutions of $\mathrm{ZnSO}_{4} \cdot 7 \mathrm{H}_{2} \mathrm{O}(30 \mathrm{ml}, 0.05 \mathrm{M})$ and $\mathrm{NaOH}$ $(30 \mathrm{~mL})$ with concentrations from $0.1 \mathrm{M}$ to $0.3 \mathrm{M}$ were prepared.

Table 1 shows the concentration of $\mathrm{NaOH}$ for each of the reactions $\mathrm{A}$ to $\mathrm{H}$. For each of these experiments, the $\mathrm{NaOH}$ solution was added dropwise to the zinc sulfate solution over $3 \mathrm{~min}$. The total volume of the reaction solution for each experiment was identical. After two hours of reaction at room temperature, the various precipitates were collected and washed with water and dried at $70^{\circ} \mathrm{C}$ under reduced pressure.

A separate reaction using zinc sulfate and sodium hydroxide was conducted where the $\mathrm{OH}^{-}: \mathrm{Zn}^{2+}$ mole ratio was only $1.1: 1$. An aqueous solution of zinc sulfate heptahydrate $(30 \mathrm{~mL}, 0.1 \mathrm{M})$ was added to a sodium hydroxide solution $(33.5 \mathrm{~mL}, 0.1 \mathrm{M})$ in a single step and the reaction maintained at room temperature for $15 \mathrm{~min}$. The resultant white precipitate was separated, washed and dried at $60{ }^{\circ} \mathrm{C}$ under reduced pressure.

\section{Method of combining the reactants}

Aqueous solutions of $\mathrm{ZnSO}_{4} \cdot 7 \mathrm{H}_{2} \mathrm{O}(30 \mathrm{~mL}, 0.05 \mathrm{M})$ and $\mathrm{NaOH}$ $(30 \mathrm{~mL}, 0.2 \mathrm{M})$ were prepared. The reaction temperature was maintained at $70{ }^{\circ} \mathrm{C}$ for $2 \mathrm{~h}$. The reactants were combined using each of the following four procedures: (1) the sodium hydroxide solution was added to the zinc sulfate solution in a single step. (2) The sodium hydroxide solution was added to the zinc sulfate solution in a drop-wise manner over $3 \mathrm{~min}$. (3) The zinc sulfate solution was added to the sodium hydroxide solution in a single step. (4) The zinc sulfate solution was added to the sodium hydroxide solution in a drop-wise manner over $3 \mathrm{~min}$.

\section{Reaction temperature}

Experiments were performed with the reaction temperature maintained at $25^{\circ} \mathrm{C}, 30^{\circ} \mathrm{C}, 40{ }^{\circ} \mathrm{C}, 45^{\circ} \mathrm{C}, 50{ }^{\circ} \mathrm{C}, 55^{\circ} \mathrm{C}, 60^{\circ} \mathrm{C}, 65^{\circ} \mathrm{C}$, $70{ }^{\circ} \mathrm{C}, 75^{\circ} \mathrm{C}, 80^{\circ} \mathrm{C}, 85^{\circ} \mathrm{C}$ and $90^{\circ} \mathrm{C}$. In each case, an aqueous $\mathrm{ZnSO}_{4} \cdot 7 \mathrm{H}_{2} \mathrm{O}$ solution $(30 \mathrm{~mL}, 0.05 \mathrm{M})$ was added to an aqueous $\mathrm{NaOH}$ solution $(30 \mathrm{~mL}, 0.2 \mathrm{M})$ in a single step. The reaction mixtures were stirred for two hours after which the precipitate was separated and washed.

\section{Results and discussion}

In the current work, the variation of several reaction parameters on the resultant zinc-containing particles was investigated. The reaction parameters varied were: (i) the stoichiometry of the reactants, (ii) the method of combining the reactants, and (iii) the effect of reaction temperature.

\section{The effect of reactant stoichiometry}

To examine the effect of the stoichiometry, the mole ratio of $\mathrm{ZnSO}_{4}: \mathrm{NaOH}$ was varied from $1: 2$ to $1: 6$, and the $\mathrm{NaOH}$ added drop-wise as described in the Experimental section. This range covers mole ratios from the stoichiometric ratio $(1: 2$, reaction $\mathrm{A})$ required to convert $\mathrm{Zn}^{2+}$ to $\mathrm{ZnO}$ (eqn (10)) to an excess of $\mathrm{NaOH}$ of three times the stoichiometric ratio $(1: 6$, reaction $\mathrm{H})$.

$$
\mathrm{Zn}_{(\text {aq) }}^{2+}+2 \mathrm{OH}_{(\mathrm{aq})}^{-} \rightarrow \mathrm{ZnO}_{(\mathrm{s})}+\mathrm{H}_{2} \mathrm{O}_{(\mathrm{l})}
$$

The XRD patterns revealed that the products of reactions $A$ and $\mathrm{B}$ contained a mixture of $\varepsilon-\mathrm{Zn}(\mathrm{OH})_{2}$ and $\mathrm{ZnO}$ (see Fig. 2). This indicates that at the stoichiometric ratio, or very close to it, significant amounts of $\mathrm{Zn}(\mathrm{OH})_{2}$ remain after $2 \mathrm{~h}$ reaction time. However, increasing the mole ratio of $\mathrm{OH}^{-}: \mathrm{Zn}^{2+}$ from $2: 1$ (reaction A) to 2.3:1 (reaction $B$ ) leads to a significant decrease in the XRD signal intensity for $\varepsilon-\mathrm{Zn}(\mathrm{OH})_{2}$ compared to $\mathrm{ZnO}$. The products of the reactions with even larger mole ratios of $\mathrm{OH}^{-}: \mathrm{Zn}^{2+}$ (2.5:1 and above) contained $\mathrm{ZnO}$ only (see Fig. 2 and ESI $\dagger$ ).

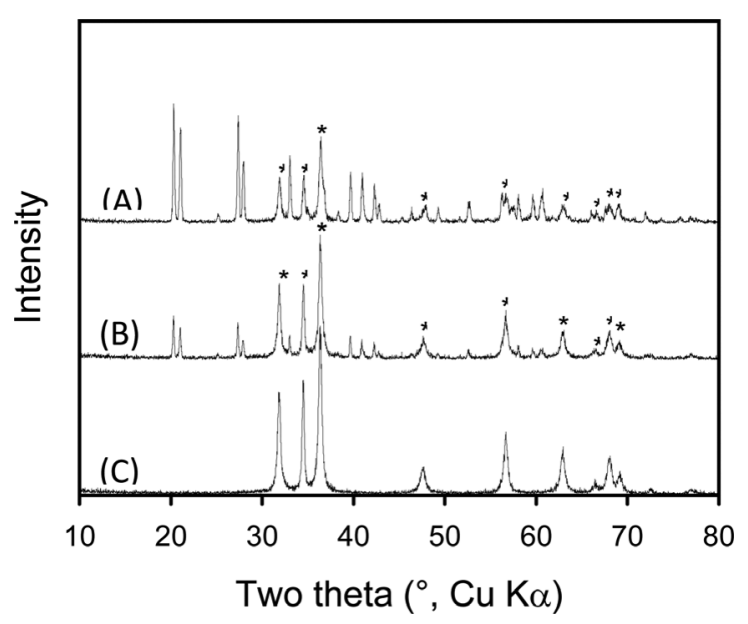

Fig. 2 X-ray diffraction data obtained from the products of reactions A, $\mathrm{B}$ and $\mathrm{C}$. The diffraction pattern for product $\mathrm{C}$ corresponds to pure $\mathrm{ZnO}$ (wurtzite). The peaks assigned to $\mathrm{ZnO}$ are indicated by * in the data for $\mathrm{A}$ and $\mathrm{B}$. Other peaks in $\mathrm{A}$ and $\mathrm{B}$ correspond to $\varepsilon-\mathrm{Zn}(\mathrm{OH})_{2}$.

TGA data (see Fig. 3 and ESI $\dagger$ ) obtained for the reaction products are consistent with the XRD data. For each of the reaction products, gradual mass loss up to a temperature of $120{ }^{\circ} \mathrm{C}$ is attributed to the loss of unbound $\mathrm{H}_{2} \mathrm{O} .{ }^{29}$ The data for the products $\mathrm{A}$ and $\mathrm{B}$ then show a rapid mass loss occurring at $120{ }^{\circ} \mathrm{C}$ due to the loss of $\mathrm{H}_{2} \mathrm{O}$ associated with the decomposition of $\mathrm{Zn}(\mathrm{OH})_{2}$ to $\mathrm{ZnO}$ and $\mathrm{H}_{2} \mathrm{O}$. $^{30}$ The amount of $\mathrm{Zn}(\mathrm{OH})_{2}$ present in the product of reaction $\mathrm{B}$ was estimated from the mass loss to be $20 \%$ of the total, which is significantly less than that from reaction A, which was estimated to be $48 \%$. No similar rapid mass loss at $120{ }^{\circ} \mathrm{C}$ was observed for the products of reactions $\mathrm{C}$ to $\mathrm{H}$, which is consistent with the XRD data that show zinc oxide is the only species present in those samples (see ESI $\dagger$ ).

As well as affecting composition, the stoichiometry of the reactants also had a significant effect on the structures of the resultant particles. Scanning electron microscopy (see Fig. 4) revealed that the product of reaction A is composed of plate-like structures mixed with ellipsoidal particles. The product of reaction 


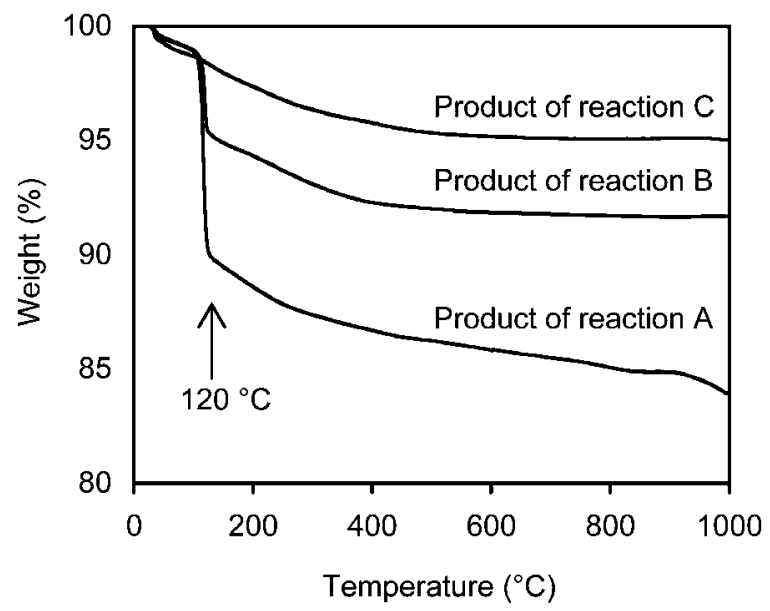

Fig. 3 Thermogravimetric analysis data for the products of reactions A, $\mathrm{B}$ and C. Heating rate was $5{ }^{\circ} \mathrm{C} \cdot \mathrm{min}^{-1}$ in an $\mathrm{N}_{2}$ atmosphere.

$\mathrm{B}$ is composed mainly of smaller well-separated particles with the particles size in the range of $100-200 \mathrm{~nm}$.

Fig. 5 shows the effect of increasing the $\mathrm{OH}^{-}: \mathrm{Zn}^{2+}$ mole ratio from $2.5: 1$ to $6: 1$. Smaller, rounder particles are produced by reactions $\mathrm{C}$ and $\mathrm{D}$ while reactions $\mathrm{G}$ and $\mathrm{H}$ produce sheet-like particles. Reactions $\mathrm{E}$ and $\mathrm{F}$ yield a mixture of the small, round particles and the sheet-like particles. XRD data show that in each case the particles have the wurtzite structure.

In reactions $\mathrm{C}$ to $\mathrm{H}$, the XRD data show diffraction patterns arising from $\mathrm{ZnO}$ only. This indicates that the larger excess of hydroxide ions (relative to reaction $\mathrm{B}$ ) drives the reaction to

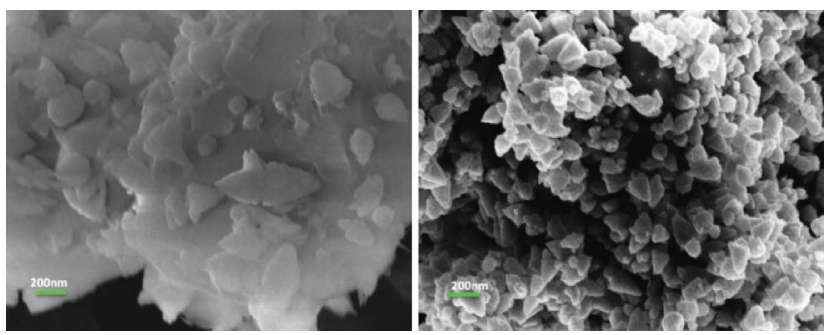

Fig. 4 SEM images of the products of reactions A (left) and B (right). From reaction (A) smaller ellipsoidal particles are formed on top of the big plate-like structures. In (B), plate-like structures cannot be detected and smaller star-like particles are dominant.

completion within $2 \mathrm{~h}$. The higher the $\mathrm{OH}^{-}: \mathrm{Zn}^{2+}$ mole ratio, the sooner the conversion of any $\mathrm{Zn}(\mathrm{OH})_{2}$ present to $\mathrm{ZnO}$ is complete and, therefore, the more time available in the reactor for coarsening of the $\mathrm{ZnO}$ crystals by the equilibrium dissolution/recrystallization processes in the solid-liquid system. ${ }^{11}$ We attribute the particle-shape transformation from small and round particles to sheet-like structures to this mechanism.

To examine the effect of sub-stoichiometric mixtures, the $\mathrm{OH}^{-}: \mathrm{Zn}^{2+}$ mole ratio was fixed at $1.1: 1(\mathrm{pH}=6)$ and the reaction conducted as described in the Experimental section. Interestingly, in this case the precipitate was shown by XRD to be zinc sulfate hydroxide hydrate $\left(\mathrm{Zn}_{4} \mathrm{SO}_{4}(\mathrm{OH})_{6} \cdot 4 \mathrm{H}_{2} \mathrm{O}\right)$. TGA revealed a mass loss of $\sim 38 \%$ up to $1000{ }^{\circ} \mathrm{C}$, which is consistent with the decomposition of $\mathrm{Zn}_{4} \mathrm{SO}_{4}(\mathrm{OH})_{6} \cdot 4 \mathrm{H}_{2} \mathrm{O}$ to $\mathrm{ZnO}$, with the complete transformation to $\mathrm{ZnO}$ requiring a temperature of $900{ }^{\circ} \mathrm{C}$ (see ESI $\dagger$ ).
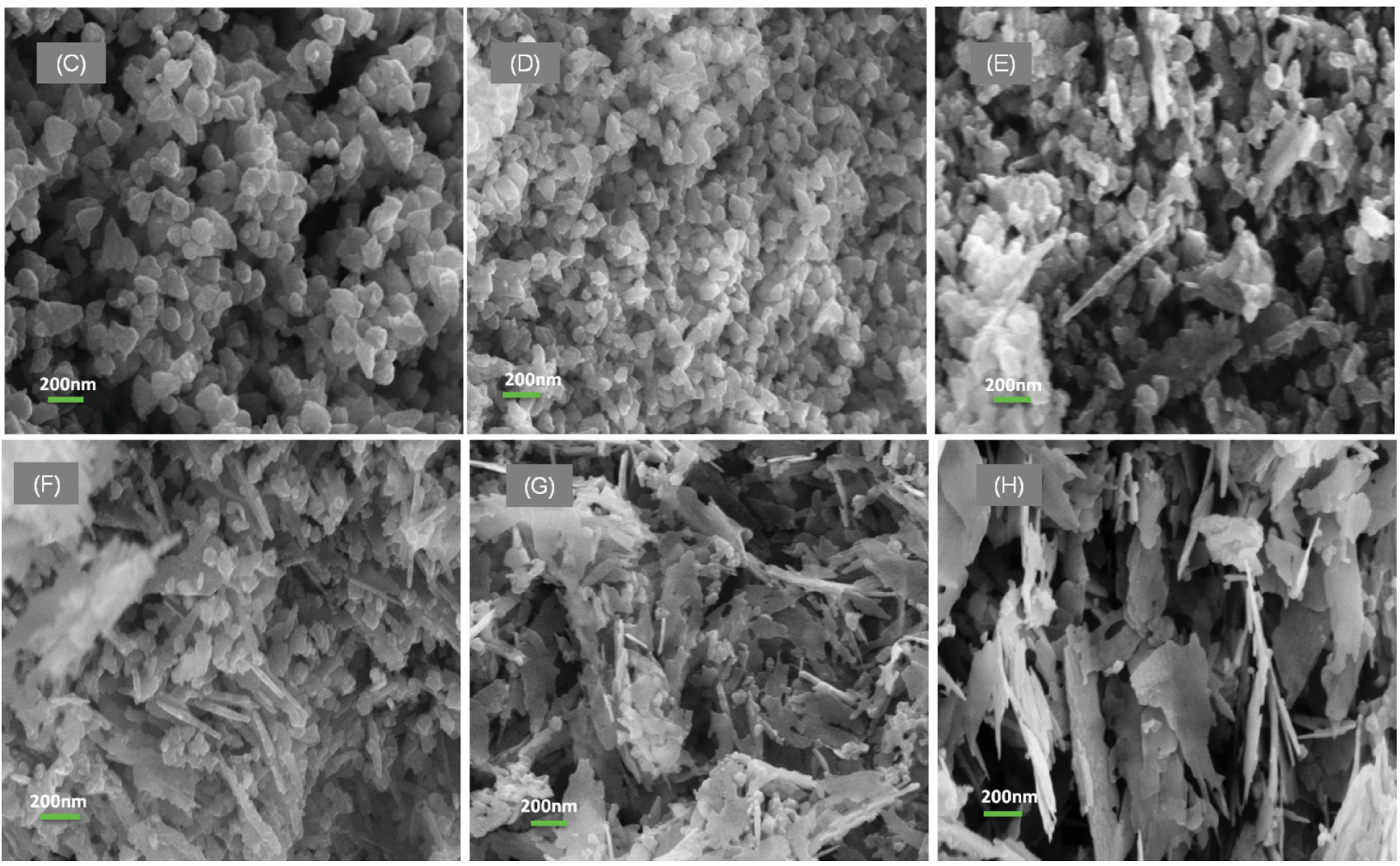

Fig. 5 SEM images of $\mathrm{ZnO}$ particles produced by the reactions $\mathrm{C}$ to $\mathrm{H}$. 


\section{Method of combining reactants}

The effect of the method of combining the reactants was investigated by altering the order and rate of addition of the zinc sulfate and sodium hydroxide solutions. This seemingly straightforward procedure has significant implications for laboratory and industrial applications of these reactions. With each experiment, XRD measurements revealed diffraction patterns consistent with $\mathrm{ZnO}$ with a hexagonal wurtzite structure for each of the four routes tested and no diffraction peaks for any other materials were detected.

SEM images obtained for the reaction products are shown in Fig. 6. Interestingly, the morphology of the $\mathrm{ZnO}$ particles differs significantly depending on the process used. When the $\mathrm{NaOH}$ solutions were added to the $\mathrm{ZnSO}_{4}$ solutions, either in a single addition or in a dropwise manner, the resultant particles are quite spherical and small, Fig. 6(a) and (b), with an average particle size of $\sim 50 \mathrm{~nm}$. Quite different particle morphologies were obtained when the addition method was reversed. With a single addition of $\mathrm{ZnSO}_{4}$ solution to $\mathrm{NaOH}$ solution, irregular, conical particles with an average particle size over $200 \mathrm{~nm}$ are formed (Fig. 6(c)). Upon dropwise addition of $\mathrm{ZnSO}_{4}$ solution to $\mathrm{NaOH}$ solution, clusters of star-shaped $\mathrm{ZnO}$ 'flowers' were generated (Fig. 6(d)). Similar morphologies have been reported for $\mathrm{ZnO}$ prepared from $\mathrm{Zn}\left(\mathrm{NO}_{3}\right)_{2}$ solutions. ${ }^{9}$ However in that instance the hydroxide was added rapidly into the nitrate precursor with vigorous stirring. This difference indicates that the processes controlling nucleation and growth of the $\mathrm{ZnO}$ are sensitive to both the reaction parameters and the identity of the counter-ion in the zinc precursor. Although the counter-ions are not incorporated into the bulk $\mathrm{ZnO}$, they seem nevertheless to play a role in directing the nature of crystal formation.

BET specific surface area measurements showed that, in the case of the single addition of $\mathrm{NaOH}$ solution to $\mathrm{ZnSO}_{4}$ solution, the surface area of the $\mathrm{ZnO}$ precipitate was $32.1 \mathrm{~m}^{2} \mathrm{~g}^{-1}$. By drop-wise addition of $\mathrm{NaOH}$ solution to $\mathrm{ZnSO}_{4}$ solution, the precipitate surface area drops to $25.9 \mathrm{~m}^{2} \mathrm{~g}^{-1}$. The star-shaped crystals formed by adding $\mathrm{ZnSO}_{4}$ solution to $\mathrm{NaOH}$ solution in a drop-wise manner had a specific surface area of only $9 \mathrm{~m}^{2} \mathrm{~g}^{-1}$. However, the irregular conical crystals formed by adding $\mathrm{ZnSO}_{4}$ solution to $\mathrm{NaOH}$ solution in a single shot had a specific surface area of $22.6 \mathrm{~m}^{2} \mathrm{~g}^{-1}$. Clearly these have a greater degree of porosity than their conical shape would imply.

These experiments show that the method of combining the reactants can have a significant effect on the particle structure. In the case where a $\mathrm{NaOH}$ solution is added to the $\mathrm{ZnSO}_{4}$ solution in a single addition, the amount of hydroxide passes the stoichiometric ratio very rapidly and zinc hydroxide species
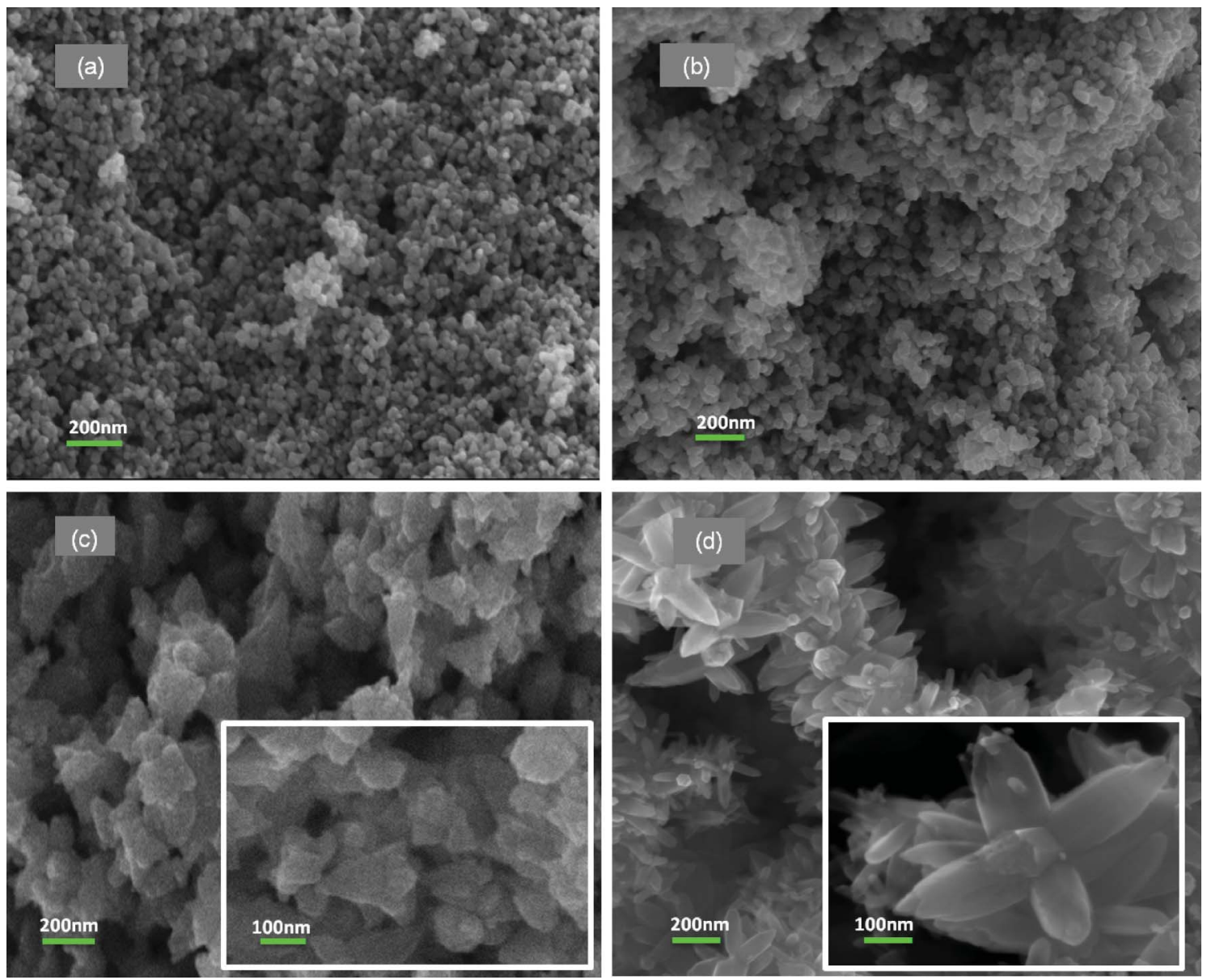

Fig. $6 \mathrm{SEM}$ images of $\mathrm{ZnO}$ particles produced at $70{ }^{\circ} \mathrm{C}$ with different feeding methods. (a) $\mathrm{NaOH}$ solution added to $\mathrm{ZnSO}_{4}$ solution in a single addition; (b) $\mathrm{NaOH}$ solution added to $\mathrm{ZnSO}_{4}$ solution in a drop-wise manner; (c) $\mathrm{ZnSO}_{4}$ solution added to $\mathrm{NaOH}$ solution in a single addition; (d) $\mathrm{ZnSO}$ s solution added to $\mathrm{NaOH}$ solution in a drop-wise manner. 
are formed followed by decomplexation to give $\mathrm{ZnO}$ in a short time. The number of nucleation sites for particle growth would therefore be large and this case results in $\sim 50 \mathrm{~nm}$ round particles. When the $\mathrm{NaOH}$ solution is added to a $\mathrm{ZnSO}_{4}$ solution in a drop-wise manner, the reaction passes slowly through the substoichiometric conditions, which can result in the formation of $\mathrm{Zn}_{4} \mathrm{SO}_{4}(\mathrm{OH})_{6} \cdot 4 \mathrm{H}_{2} \mathrm{O}$ until the mole ratio of $\mathrm{ZnSO}_{4}: \mathrm{NaOH}$ reaches at least $1: 2$. At this mole ratio, substitution of sulfate ions with hydroxide ions will occur. Upon further addition of hydroxide, the reaction continues to completion.

On the other hand, significant changes in the particles are observed by reversing the order of addition. In these cases, the formation of zinc sulfate hydroxide complexes do not occur as $\mathrm{OH}^{-}$is in considerable excess at all times during the reaction. In the single-step addition of a $\mathrm{ZnSO}_{4}$ solution to a $\mathrm{NaOH}$ solution, the reaction appears to proceed rapidly from soluble zinc complex to formation of $\mathrm{ZnO}$ nuclei. Fewer nuclei are formed, and these lead to the growth of the $\sim 200 \mathrm{~nm}$ big conical particles. Interestingly, by drop-wise addition of the $\mathrm{ZnSO}_{4}$ solution to a $\mathrm{NaOH}$ solution, clusters of $\mathrm{ZnO}$ star-like particles dominate and the surface area drops dramatically in comparison. In the early stages of addition, the mole ratio of $\mathrm{ZnSO}_{4}: \mathrm{NaOH}$ is very small and therefore the higher-order hydro-complexes of zinc form rapidly followed by decomplexation to form $\mathrm{ZnO}$ nuclei. Since in all stages of addition $\mathrm{OH}^{-}$was in excess, the excess of hydroxide catalyses the formation of $\mathrm{ZnO}$ (see below). At the same time, $\mathrm{ZnO}$ formed tends to grow on the limited number of $\mathrm{ZnO}$ nuclei formed in the early stages of the reaction. Thus, highly crystalline clusters of $\mathrm{ZnO}$ flowers with a relatively low specific surface area are formed.

\section{The effect of temperature}

In these experiments, the mole ratio of $\mathrm{ZnSO}_{4}: \mathrm{NaOH}$ was fixed at 1:4 and the $\mathrm{ZnSO}_{4}$ solution was added to the $\mathrm{NaOH}$ solution in a single step as described in the Experimental section. XRD patterns of the products showed only $\mathrm{ZnO}$ with the hexagonal wurtzite structure (see ESI $\dagger$ ).

Fig. 7 (see also ESI $\dagger$ ) shows that the morphology of $\mathrm{ZnO}$ synthesized is sensitive to the reaction temperature. At room temperature, irregular and sharp particles including needle-like particles in the agglomerated form are dominant. Increasing the temperature to $40{ }^{\circ} \mathrm{C}$ causes the sharpness of the aggregates to decrease and both plate-like and star-like particles can be observed. By $45{ }^{\circ} \mathrm{C}$, star-like particles are dominant. Average particle size has decreased relative to that of reaction at $40{ }^{\circ} \mathrm{C}$. Further increase in the temperature to $90{ }^{\circ} \mathrm{C}$ results in the particles systematically becoming more equiaxed (sphere-like), less starlike, and smaller. By $90{ }^{\circ} \mathrm{C}$ the particles are about $100 \mathrm{~nm}$ in diameter which is about a third or so of the diameter of particles produced at $45^{\circ} \mathrm{C}$. The heights and areas of the $\{101\},\{002\}$ and $\{001\}$ diffraction peaks showed no significant change with temperature, from which it can be concluded that the crystallite size did not change significantly with temperature. Increasing the reaction temperature has two effects: an increase in the formation of nuclei, which would promote smaller particles in the endproduct ${ }^{15}$ and a faster rate of decomposition of zinc-hydroxocomplexes to $\mathrm{ZnO}$, which results in the growth and coarsening of end-products. In this case, however, the increased rate of nucleation seems to dominate as the temperature of the reaction is increased in this series of reactions. The overall trend in BET specific surface area with temperature (Fig. 8) is upwards, in support of the observation that particle sizes decrease as the temperature of reaction is increased.

Factors other than an increased rate of nucleation may also contribute to the change in morphology with temperature. In particular, the stability of the soluble zinc hydroxy-complexes decreases as the temperature increases, which leads to more $\mathrm{ZnO}$
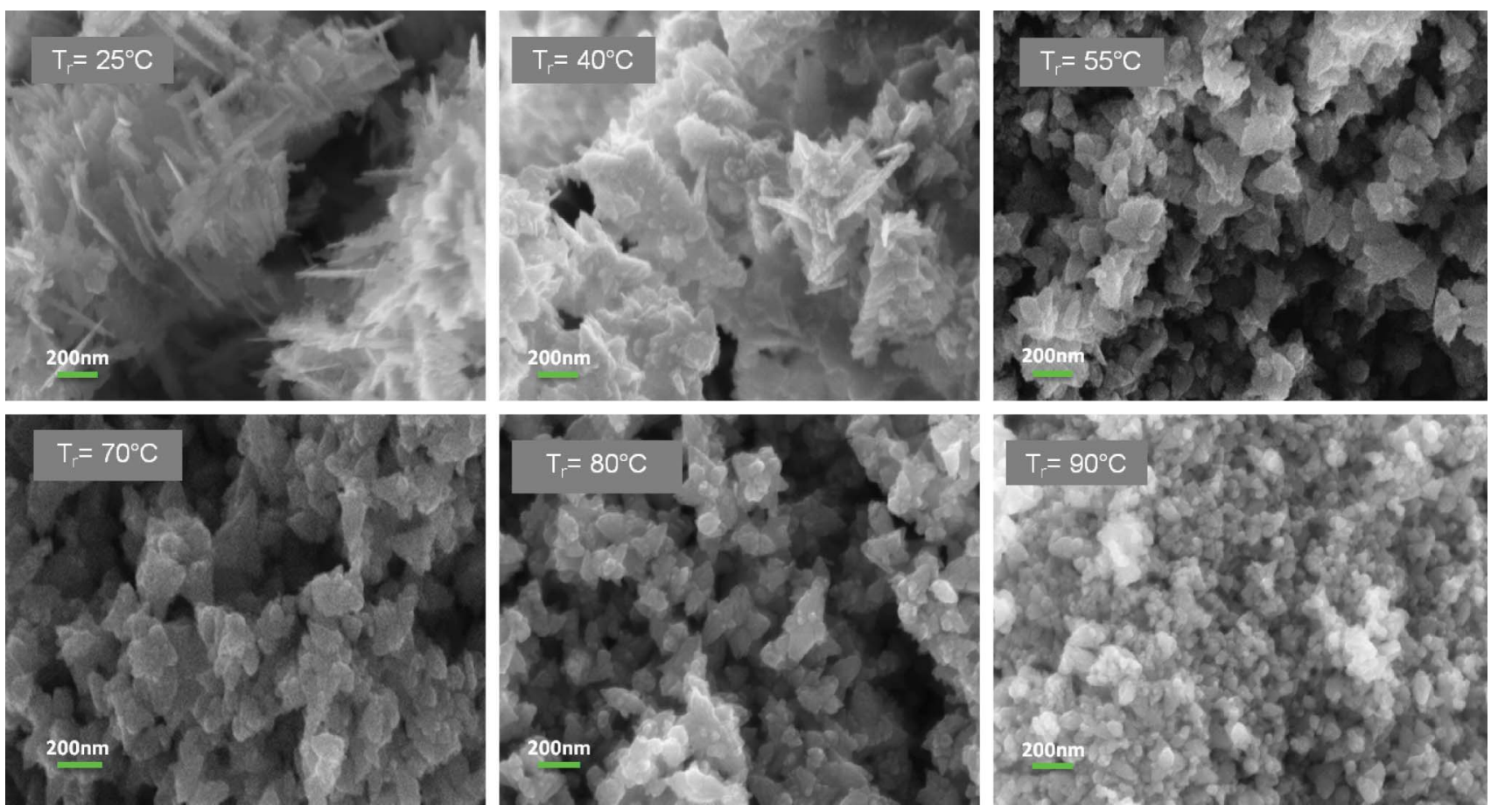

Fig. 7 SEM images of $\mathrm{ZnO}$ particles synthesized at different temperatures. 


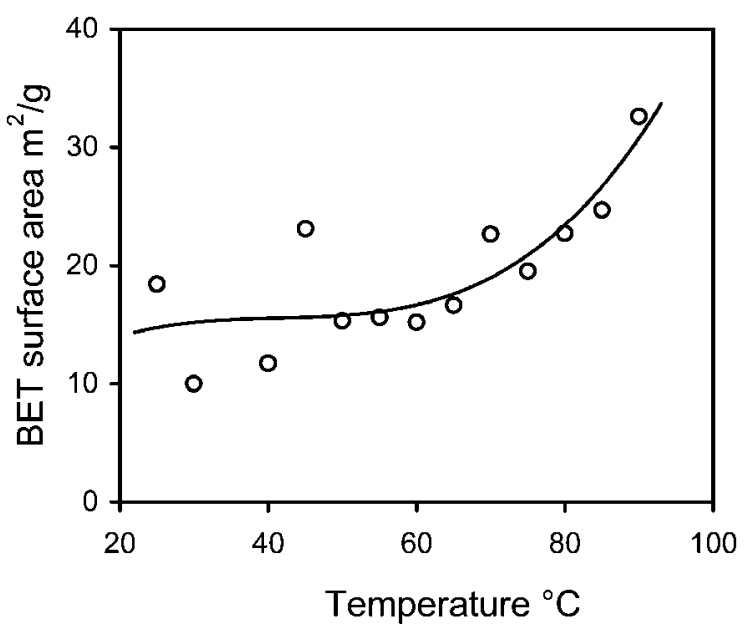

Fig. 8 BET specific surface area $\left(\mathrm{m}^{2} \mathrm{~g}-1\right) v$. reaction temperature in the range of 25 to $90{ }^{\circ} \mathrm{C}$. The trend line shown was obtained by polynomial regression and is provided as a guide to the eye.

precipitating from the solution phase. Increasing the temperature from $25{ }^{\circ} \mathrm{C}$ to $90{ }^{\circ} \mathrm{C}$ decreases the amount of soluble zinc species almost by one order of magnitude which results in more precipitation by almost one order of magnitude accordingly. ${ }^{14}$ Another consideration is that decomplexation reactions of soluble $\mathrm{Zn}(\mathrm{OH})_{3}{ }^{-}$and $\mathrm{Zn}(\mathrm{OH})_{4}{ }^{2-}$ to $\mathrm{ZnO}$ are slightly endothermic, so that increasing the solution temperature favors the precipitation of $\mathrm{ZnO}$.

\section{The catalytic effect of $\mathrm{OH}^{-}$}

We attribute the dramatic change in the mass fraction of zinc hydroxide compared to zinc oxide upon proceeding from reaction A to reaction $\mathrm{C}$ to the presence of hydroxide ions in excess of the stoichiometric ratio, which we propose may have a catalytic effect on the transformation of zinc hydroxide to zinc oxide. To examine the pathways that result in the formation of zinc oxide in aqueous systems, standard enthalpies and Gibbs free energies were calculated for a number of reactions (see Scheme 1). Thermodynamic calculations show that the Gibbs free energy for all the reactions leading to zinc oxide is negative.

Starting with aqueous $\mathrm{Zn}^{2+}$ ions (or more formally $\mathrm{Zn}\left(\mathrm{H}_{2} \mathrm{O}\right)_{6}{ }^{2+}$, which is slightly acidic in nature, ${ }^{14,17}$ ) addition of a substoichiometric amount of $\mathrm{OH}^{-}$initially gives the $\mathrm{Zn}(\mathrm{OH})^{+}$species. Formation of cationic species such as $\mathrm{Zn}(\mathrm{OH})^{+}, \mathrm{Zn}_{2}(\mathrm{OH})^{3+}$, $\mathrm{Zn}_{4}(\mathrm{OH})_{4}{ }^{4+}$ in acidic or near-neutral solutions has been reported ${ }^{17}$ although a zinc sulfate hydroxide species also forms in the present case, as discussed separately below. Addition of a second hydroxide ion results in the formation of $\mathrm{Zn}(\mathrm{OH})_{2}$, which has low solubility in water $\left(K_{\mathrm{sp}}=3.5 \times 10^{-17}\right.$ at $\left.25^{\circ} \mathrm{C}\right) .{ }^{14,18}$ Crystalline $\varepsilon-\mathrm{Zn}(\mathrm{OH})_{2}$ is thermodynamically metastable with respect to crystalline $\mathrm{ZnO}$ at $25^{\circ} \mathrm{C}$ with $\Delta G^{\circ}{ }_{\mathrm{r}}=-4.07 \mathrm{~kJ} \mathrm{~mol}^{-1}$ (see dotted line in Scheme 1) but the rate of transition of solid $\varepsilon-\mathrm{Zn}(\mathrm{OH})_{2}$ to $\mathrm{ZnO}$ is negligible at ambient temperature ${ }^{17,24}$ as the solid state reaction is endothermic $\left(\Delta H^{\circ}{ }_{\mathrm{r}}=+5.62 \mathrm{~kJ} \mathrm{~mol}^{-1}\right.$ if the data of Zhang and Muhammed are used. $\left.{ }^{17}\right) \Delta G^{\circ}{ }_{\mathrm{r}}$ for the transformation of aqueous zinc hydroxide to zinc oxide and water is negative but the rate of this reaction in these experiments is small due to the low solubility of zinc hydroxide. Solid zinc hydroxide has been reported to remain unchanged after six months in water at room temperature; at $65^{\circ} \mathrm{C}$ no significant change was observed up to three weeks, at $75^{\circ} \mathrm{C}$ conversion was less than $10 \%$ in three weeks but at $100{ }^{\circ} \mathrm{C}$ the zinc hydroxide formed $\mathrm{ZnO}$ in less than one hour. ${ }^{24}$

The addition of hydroxide in excess relative to the stoichiometric ratio contributes to the solubilisation of crystalline zinc hydroxide by formation of soluble hydroxo-complexes of zinc (eqn (4) and (5)). These complexation reactions followed by decomplexation (eqn (8) and (9)) are the main contributors to the room temperature formation of $\mathrm{ZnO}$ in the current work. The driving force for the precipitation of $\mathrm{ZnO}$ from higher-order hydroxo-complexes of zinc

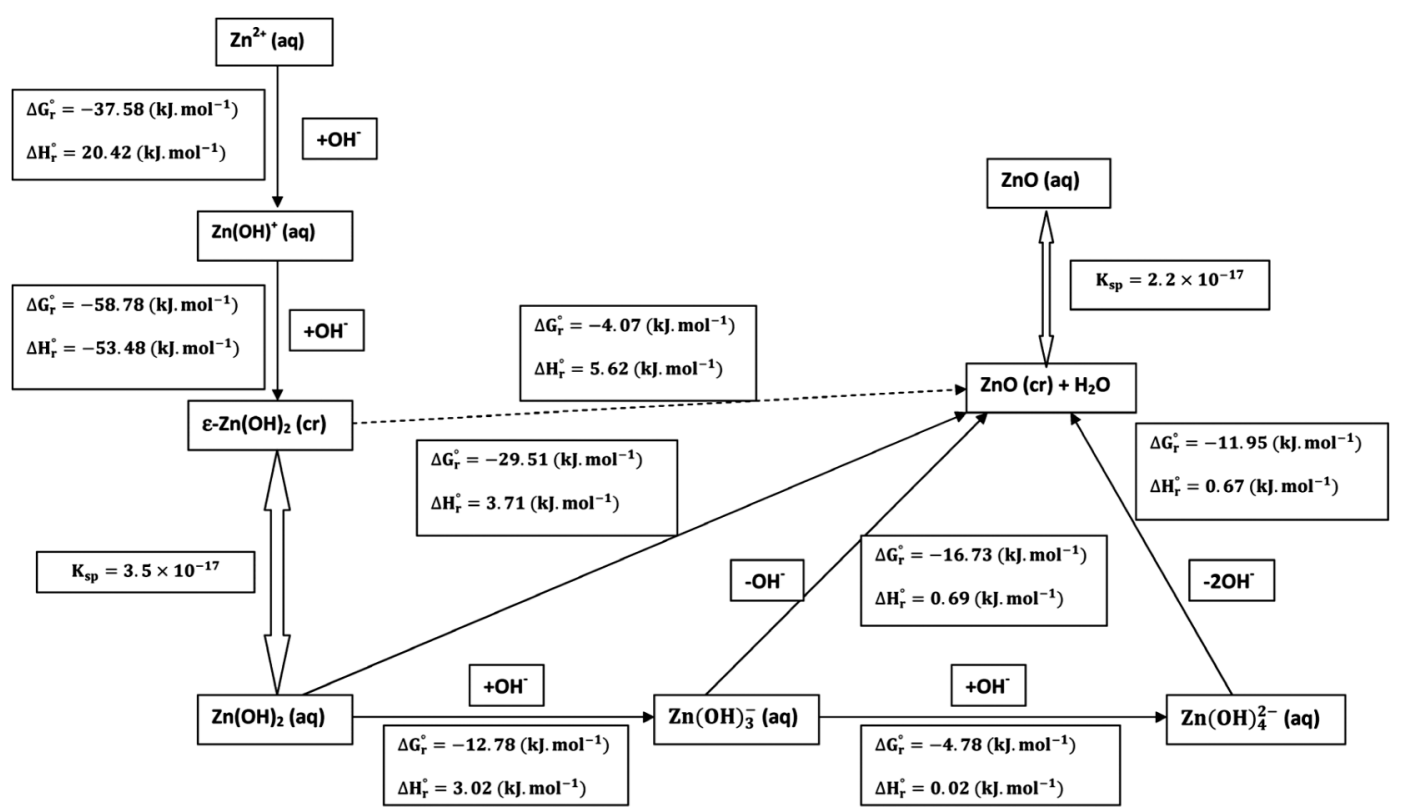

Scheme 1 Thermodynamic data for the formation of $\mathrm{ZnO}$ from $\mathrm{Zn}^{2+}$ and $\mathrm{OH}^{-}$at $298 \mathrm{~K}$ and $1 \mathrm{~atm}$. Standard states have been assumed. For consistency, data from Zhang and Muhammed were used. ${ }^{17}$ 
is the thermodynamic instability of such complexes with respect to $\mathrm{ZnO}$. Importantly, hydroxide ions are returned to the reaction mixture upon formation of $\mathrm{ZnO}$. After completion of the reaction, the system is basic and the only product is stable crystalline $\mathrm{ZnO}$ (in equilibrium with soluble $\mathrm{ZnO}$ ) as well as water from the reaction. By increasing the hydroxide concentration over the stoichiometric ratio, formation of $\mathrm{ZnO}$ from $\mathrm{Zn}(\mathrm{OH})_{2}$ is accelerated. Therefore, hydroxide ions in excess of the stoichiometric ratio have a catalytic effect on the formation of $\mathrm{ZnO}$ in water.

\section{Conclusions}

The morphology of $\mathrm{ZnO}$ and $\mathrm{Zn}(\mathrm{OH})_{2}$ precipitates formed from $\mathrm{ZnSO}_{4}$ solutions is acutely sensitive to the $\mathrm{pH}$, temperature and method by which the reactants are mixed. For molar ratios of $\mathrm{ZnSO}_{4}$ to $\mathrm{NaOH}$ between $1: 2$ and $1: 2.5$ the precipitate that forms first is $\mathrm{Zn}(\mathrm{OH})_{2}$. In aqueous conditions $\mathrm{Zn}(\mathrm{OH})_{2}$ is converted to $\mathrm{ZnO}$ by a hydroxide-catalyzed process, with the process accelerating as $\mathrm{pH}$ is increased. A basic zinc sulfate is precipitated when the molar ratio is below $1: 2$ while no precipitate is formed if sufficient base is present to raise the $\mathrm{pH}$ above 12 and solubilize the $\mathrm{Zn}$ as $\mathrm{Zn}(\mathrm{OH})_{4}{ }^{2-}$. The order of additions is also an important parameter. If small nanoparticles are desired then it is essential to add the $\mathrm{NaOH}$ into the $\mathrm{ZnSO}_{4}$ precursor. This ensures that prolific nucleation of $\mathrm{Zn}(\mathrm{OH})_{2}$ particles occurs because conditions become favorable for precipitation almost immediately. When the addition is done in the opposite sense (i.e. $\mathrm{ZnSO}_{4}$ into $\mathrm{NaOH}$ ) fewer nuclei are formed and the final particles are larger and more crystalline because the initial conditions favor formation of soluble complexes rather than precipitates. In all cases, it appears that the $\mathrm{Zn}(\mathrm{OH})_{2}$ converts to $\mathrm{ZnO}$, with the rate of the process increased by both temperature and $\mathrm{pH}$.

\section{Acknowledgements}

This work was supported by PT. Indo Lysaght (Indonesia).

\section{Notes and references}

1 Z. L. Wang, J. Phys.: Condens. Matter, 2004, 16, R829-R858.

2 Ü. Özgür, Y. I. Alivov, C. Liu, A. Teke, M. A. Reshchikov, S. Doğan, V. Avrutin, S.-J. Cho and H. Morkoçd, J. Appl. Phys., 2006, 98, 041301.
3 C. Klingshirn, Phys. Status Solidi B, 2007, 244, 3027-3073.

4 A. Becheri, M. Dürr, P. L. Nostro and P. Baglioni, J. Nanopart. Res., 2008, 10, 679-689.

5 G. Auer, W.-D. Griebler and B. Jahn, Industrial Inorganic Pigments, Wiley-VCH Verlag GmbH \& Co. KGaA, Weinheim, 2005.

6 S. Mahmud, M. J. Abdullah, G. A. Putrus, J. Chong and A. K. Mohamad, Synth. React. Inorg., Met.-Org., Nano-Met. Chem., 2006, 36, 155-159.

7 S. Baruah and J. Dutta, Sci. Technol. Adv. Mater., 2009, 10, 013001.

8 J. J. Richardson and F. F. Lange, Cryst. Growth Des., 2009, 9, 25702575.

9 S. Sepulveda-Guzman, B. Reeja-Jayan, E. d. 1. Rosa, A. Torres-Castro, V. Gonzalez-Gonzalez and M. Jose-Yacamane, Mater. Chem. Phys., 2009, 115, 172-178.

10 R. A. McBride, J. M. Kelly and D. E. McCormack, J. Mater. Chem., 2003, 13, 1196-1201.

11 K. Govender, D. S. Boyle, P. B. Kenway and P. O’Brien, J. Mater. Chem., 2004, 14, 2575-2591.

12 A. P. A. Oliveira, J. F. Hochepied, F. Grillon and M.-H. Berge, Chem. Mater., 2003, 15, 3202-3207.

13 J. Xie, P. Li, Y. Li, Y. Wang and Y. Wei, Mater. Chem. Phys., 2009, 114, 943-947.

14 K. Jacobs, D. Balitsky, P. Armand and P. Papet, Solid State Sci., 2010, 12, 333-338.

15 A. Goux, T. Pauporté, J. Chivot and D. Lincot, Electrochim. Acta, 2005, 50, 2239-2248.

16 C. Debiemme-Chouvy and J. Vedel, J. Electrochem. Soc., 1991, 138, $2538-2542$.

17 Y. Zhang and M. Muhammed, Hydrometallurgy, 2001, 60, 215-236.

18 R. A. Reichle, K. G. McCurdy and L. G. Hepler, Can. J. Chem., 1975, 53, 3841-3845.

19 T. P. Dirkse, J. Electrochem. Soc., 1986, 133, 1656-1657.

20 A. D. James, C. S. Noel and K. D. Steven, Environ. Prog., 1998, 17, 1-8.

21 W. Zhang and K. Yanagisawa, Chem. Mater., 2007, 19, 2329 2334.

22 C. Chambers and A. K. Holliday, Modern Inorganic Chemistry, The Butterworth Group, London, 1975.

23 G. Brauer, Handbook of Preparative Inorganic Chemistry, Academic Press Inc., London, 1963.

24 H. G. Dietrich and J. Johnston, J. Am. Chem. Soc., 1927, 49, 1419-1431.

25 J. Zhang, L. Sun, J. Yin, H. Su, C. Liao and C. Yan, Chem. Mater., $2002,14,4172-4177$.

26 A. N. Maslii, M. S. Shapnik and A. M. Kuznetsov, Russ. J. Electrochem., 2001, 37, 615-622.

27 P. Ramamurthy and E. A. Secco, Can. J. Chem., 1968, 46, 36053606.

28 J. A. Dean, Lange's Handbook of Chemistry, Mc Graw Hill, Inc, New York, 1999.

29 J. Lu, K. M. Ng and S. Yang, Ind. Eng. Chem. Res., 2008, 47, 10951101.

30 A. Shaporev, V. Ivanov, A. Baranchikov, O. Polezhaeva and Y. Tret'yakov, Russ. J. Inorg. Chem., 2007, 52, 1811-1816. 